\title{
Study of the application of Acoustic Emission technology for on-line monitoring of bubble phenomena and flow patterns in two-phase gas-liquid flow
}

\author{
S. Husin ${ }^{1}$, A. Addali ${ }^{2}$ \& D. Mba ${ }^{2}$ \\ ${ }^{1}$ Universiti Kuala Lumpur Malaysian Spanish Institute, Malaysia \\ ${ }^{2}$ Cranfield University, School of Engineering, UK
}

\begin{abstract}
An investigation into single bubble dynamics detection in a liquid-filled column, and monitoring and measurement of gas void fraction in a horizontal pipe using $\mathrm{AE}$ technology has been performed. A correlation between Acoustic Emission (AE) and Gas Void Fractions in two-phase gas-liquid flow in a horizontal pipe has been established from this work. The results demonstrate the feasibility of employing AE technology as an on-line monitoring tool for bubble dynamics and flow patterns in two-phase gas-liquid flow in pipes.

Keywords: Acoustic Emission (AE), gas bubble, two-phase flow.
\end{abstract}

\section{Introduction}

Acoustic Emission (AE) technology is very practical as a passive and intrusive tool for the monitoring of material processes and for the testing, detection, and characterization of any present defect or particular event. AE describes the process associated with the emission and propagation of strain waves, resulting from localized modifications of materials [1]. If there is a transient release of energy within a solid/medium, it is dissipated in the form of elastic waves which can be detected on the surface by transducers. This process is known as Acoustic Emission (AE) [2]. The frequency of the elastic wave is usually beyond the human hearing threshold $(25 \mathrm{kHz})$. The sensitivity of the AE transducer which is made of piezoelectric material can detect sound beyond the human range of hearing, i.e. $25 \mathrm{kHz}-1 \mathrm{MkHz}$ is regarded as the backbone of $\mathrm{AE}$ technology. 
The application of AE technology as a monitoring tool in two phase gasliquid flow in pipeline is relatively new. It is gaining attention because the advantages of the AE technology over the other measuring techniques has been realised. It offers significantly reduced installation time as it can be fitted nonintrusively to the pipe; in addition, the cost of the AE technology is considerably less than existing systems. An active-observing benefit from the on-line monitoring technique offered by AE technology provides information of current process conditions such as flow patterns and velocity in a pipe.

Recently, AE technology's application as a measurement and monitoring tools for the two-phase gas-liquid system has been explored. Yen and $\mathrm{Lu}$ [3] employed the AE technique, combined with artificial neural network technology in their experiment to determine and observe the flow patterns (bubbly, slug, churn and annular flow) of the two-phase flow in a vertical column bed. In a very recent study, 2009, the AE technology was employed in the monitoring of slugs and in the measurement of their characteristics - gas void fraction [4]. It is concluded therefore that the GVF can be determined by measurement of the AE. However, its applications in multi-phase and two-phase gas-liquid systems are relatively few and still in their infancy stage. The opportunity for on-line monitoring in two-phase flow with AE offers industry a complementary technology. A passive AE technology offers an alternative to the intrusive ultrasonic methods.

\section{Background work of bubble detection}

The concept of sound propagation interference which contributed by surface discontinuities in solid material particularly metal, has been used in detecting surface defects such as cracking and pitting. Such defects are known as mechanical sources in moving parts/elements such as gears, bearings etc. In addition, in a fluid system the AE could be attenuated/excited by sources such as bubble activities including bubble formation, coalescence, break-up and collapse/burst [5-7]. The other sources of AE generation in liquid flow are flow turbulence, flow past restrictions, liquid flashing and recirculation/turbulence $[5,8-10]$. Those sources caused a change of pressure wave or sound pressure in liquid. The establishment of AE from bubble activities in two phase gas-liquid flow is interesting and has motivated this technique to be used for correlation with gas void fraction in pipeline.

Phenomena in two-phase flow are quite complex and knowledge of two phase gas-liquid flow and measuring techniques as related to key parameters (e.g. phase velocities) and bubble activities such as bubble inception, coalesce, breakup and collapse in liquid are not sufficient so far. In addition, two phase gasliquid flow plays an important role in industrial applications; hence, it seems a strong reason for two-phase flow to be investigated [11].

Kloeppel [12] relates the sound generated from bubble collapse with liquid wave where noted that the sonic energy is converted into mechanical energy, causing shock waves and motion in the surrounding liquid. In another reference, Ross [13] noted that the pressure pulse emitted by collapsing bubbles is of 
sufficient amplitude to produce shock waves. De-Bosset et al. [14] used a pressure sensor to record the pressure change from bubble activities and the results confirmed the association of pressure peaks with the shockwaves emitted at cavity inception and collapse. It has been observed by many researchers that the pulse started just as the bubble separates/pinches off from the nozzle [15-18]. Beside bubble inception and collapse events, bubble break-up and coalescence are also sources of sound in liquid [5, 15, 19, 20].

Liquid stream in a pipeline is complicated with inter-phases induced due to turbulence flow. Turbulence flow caused rupture of liquid where cavities were thus generated [21]. This type of cavity is known as cavitation bubble. Turbulence flow also caused bubbles' coalescence which contributed to a greater size. The bigger the size of bubble, the higher bubble potential energy contained $[14,22-24]$. The generated bubble/cavity as a result of the turbulence flow in a pipe is commonly categorized as transient cavity and generally exists for less than one cycle before collapsing violently [25]. Rebounds from a relatively bigger size would probably be detected by transducers. Multiple bubbles collapse/burst or rebound: the sound produced would increase whilst the frequency remained the same. A single bubble activity generates an AE transient signal in the waveform. Multiple bubbles' activities (from bubbles cloud or higher bubble population); inception, coalescence, break-up and burst resulted in a mixed signal type of waveform.

There are four types of flow regimes has been characterized in two-phase flow in a horizontal pipe; stratified, wavy, bubble, slug, and annular flow. The flow patterns are dependent on the phase flow rates, see figure 1 [26].

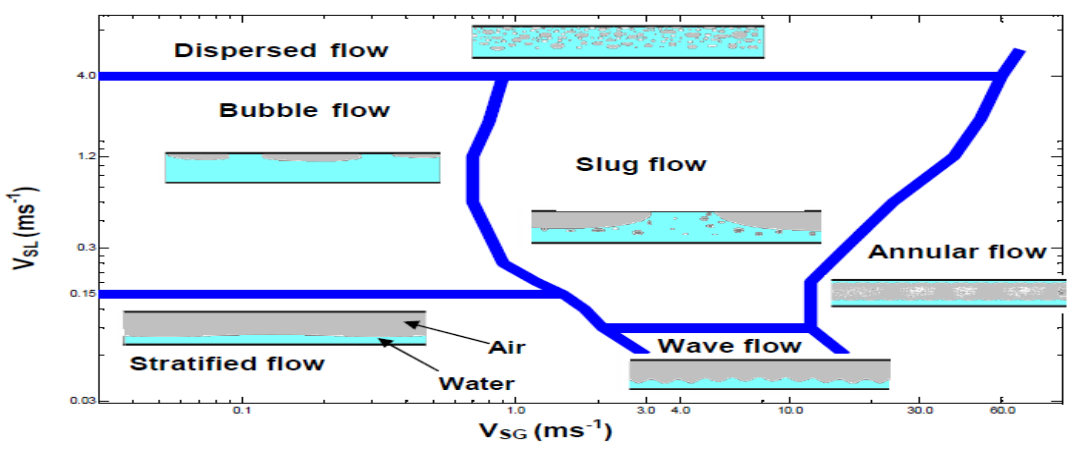

Figure 1: $\quad$ Horizontal flow regimes map [26].

Briefly, it can be explained that the gradual increase in liquid velocity (VSL) will result in converting the wavy flow to what is described as slug flow. In this flow pattern large waves of liquid form a slug that can fill the whole crosssection of the pipe leading to the blocking of the downstream gases, see figure 1 and 9. In the case of slug flow in the pipeline, the elongated bubble induces greater interfaces where the concentration of bubbles at its nose and tail would collapse/burst at the free surface of a film region, see figure 9. This phenomenon is one the reasons why at the presence of slug flow, the AE generated is higher. 
The contribution of bubbles, particularly at the region of nose and tail of liquid slug body, can be illustrated as below and well explained in reference [4].

Evidence has been provided by many researchers that the acoustic pressure waves are detected in the initial shape distortion of bubble formation phase when a bubble detaches from the nozzle and in the subsequent collapse phase. Pressure impulses depend on the bubble energy where it is estimated only $\sim 10$ to $15 \%$ of the bubble energy contributed to the generation of pressure impulses [27]. High pressures arise from the bubble activities (formation and collapse) which cause compression to liquid and become an important factor in the motion near the end of collapse when eventually the pressure pulse radiated from the bubble collapse centre will take the form of a shockwave [28]. Shockwave then propagates with a direct function of the pressure at any given point: the higher the pressure, the greater the velocity of sound [29]. This shock wave propagation can be detected by underwater sensor pressures such as hydrophone, microphones and $\mathrm{AE}$ transducers.

Based on the evidence from a background survey and previous work at Cranfield University, it is determined that the AE technology is feasible for detecting gas bubble activities; formation, coalescence and collapse. Furthermore, it is strongly believed that pressure pulses associated with the bubble formation, coalescence in the liquid and burst at free surface are potential sources for AE. This gives an indication that correlates with gas phase/Gas Void Fraction (GVF) measurement in a horizontal pipe.

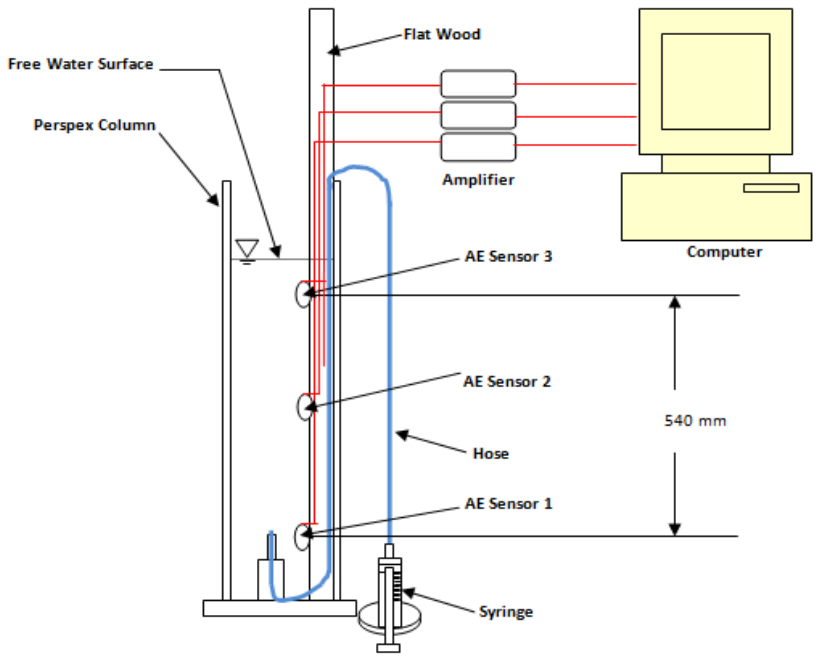

Figure 2: Schematic diagram of the experiment for $\mathrm{AE}$ single bubble detection.

\section{Detection of a single bubble formation and burst}

The apparatus employed for AE detection of a single bubble is shown in figure 6 . The rig consists of a column filled with water and salt-water for comparison on 
the effect of liquid viscosity on the emission of bubble activities. A single bubble in the column was produced with a syringe. Sensor-1 was positioned at the bottom near to the nozzle; sensor-3 was positioned near to the water free surface; sensor-2 was positioned in mid-way of bubble travelling. The transducers had an operating frequency of $100-750 \mathrm{kHz}$ and a pre-amplification at $60 \mathrm{~dB}$ was applied. The sampling rate for acquisition of $\mathrm{AE}$ waveforms was $2 \mathrm{MHz}$. Threshold level $24 \mathrm{~dB}$ was set above the electronic background noise of the acquisition system.

\section{Experimental results}

A waveform associated with a single bubble inception is shown in figure 3 (top). A corresponding time-frequency plot was generated by the AGU-Vallen software tool, see figure 3 (bottom) which showed the intensity of frequency over the time of the signal captured during bubble inception.

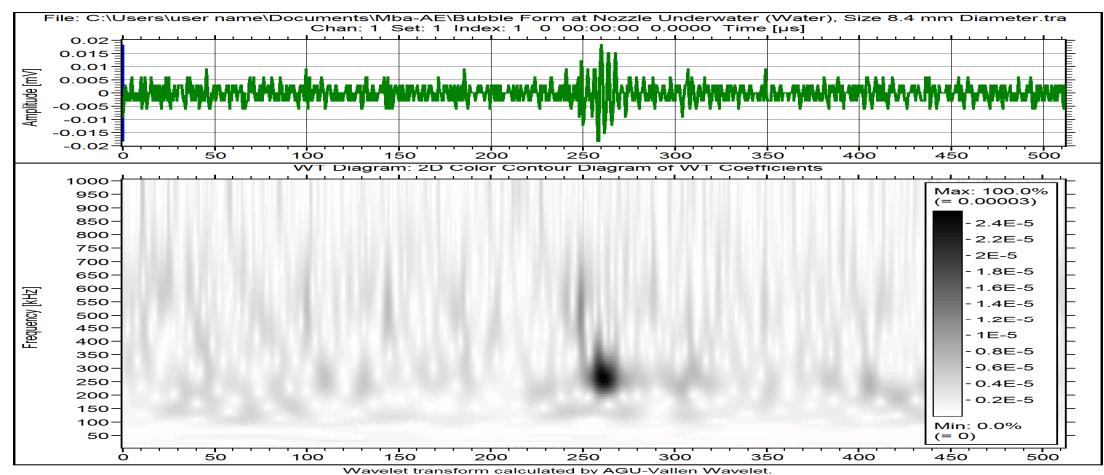

Figure 3: AE from a single bubble inception (nozzle size $8.4 \mathrm{~mm}$ in water $(1 \mathrm{cP}))$.

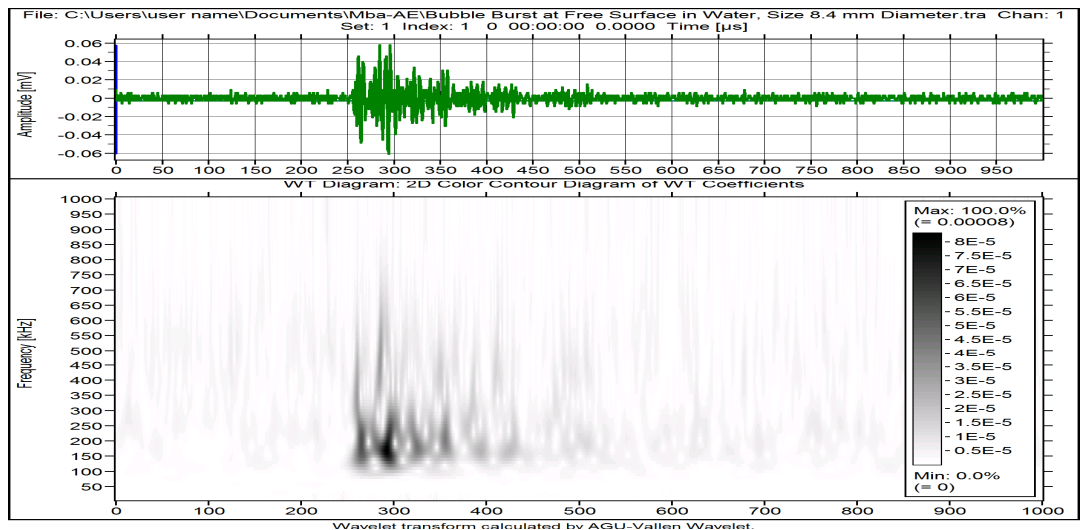

Figure 4: AE from a single bubble burst from nozzle size $8.4 \mathrm{~mm}$ in water $(1 \mathrm{cP})$. 
The waveform and wavelet plot from the data acquired from bubble burst at the free surface is presented in figure 4 . Both figures 3 and 4 show that the bubble inception or burst has high frequencies of up to $750 \mathrm{kHz}$ at the start of the AE event.

The findings demonstrated that $\mathrm{AE}$ technology is very sensitive where it can differentiate the emission from bubble activity with difference test parameters. The magnitude of AE energy from bubble burst was dependent on liquid properties; surface tension and viscosity, as well as the bubble size, see figure 5.

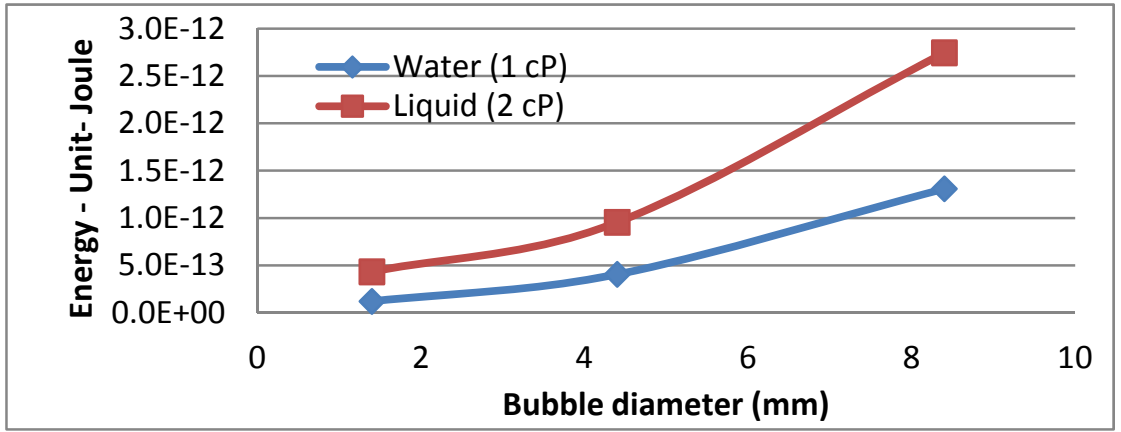

Figure 5: Average of energy from a single bubble burst as a function of bubble size and viscosity.

\section{Monitoring gas void fraction in horizontal pipe with $\mathrm{AE}$}

Having showed that AE has been successfully detected from a single bubble activity (inception and burst), the application of this technique (AE technology) has been explored to assess whether AE could be correlated to Gas Void Fraction (GVF). In this experiment, three important parameters have been used that commonly used to describe two-phase flow: Gas Void Fraction, Superficial Liquid Velocity and Superficial Gas Velocity. Briefly, GVF is defined as the ratio of the volumetric of the gas to the total volumetric flow-rate. In two-phase flow Superficial Liquid Velocity (VSL) is defined as the volumetric flow rate of liquid phase divided by the cross-sectional area of the pipe. Superficial Gas Velocity (VSG) is defined as the volumetric flow rate of gas phase divided by the cross-sectional area of the pipe [30].

Liquid superficial velocity (VSL) ranging from $0.3 \mathrm{~m} / \mathrm{s}$ to $1.0 \mathrm{~m} / \mathrm{s}$ at increments of $0.1 \mathrm{~m} / \mathrm{s}$, and the gas superficial velocity (VSG) ranged from 0.8 $\mathrm{m} / \mathrm{s}$ to $9.4 \mathrm{~m} / \mathrm{s}$ at increments of $0.2 \mathrm{~m} / \mathrm{s}$ have been employed in this experiment. For a reference/comparison measurement, conductivity rings which are commonly used for GVF measuring devices were installed in the experimental apparatus for gas void fraction (GVF) measurements (see fig 6 and 7). Correlation of $\mathrm{AE}$ energy with the value obtained from conductivity rings then has been performed. 


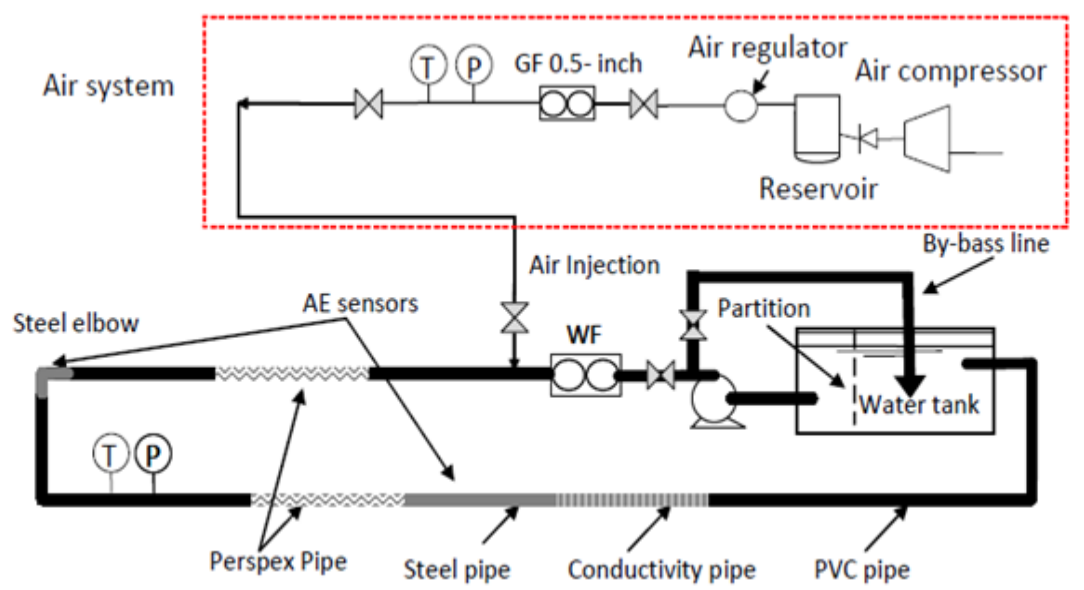

Figure 6: Experimental setup for two-phase GVF monitoring and measurement.

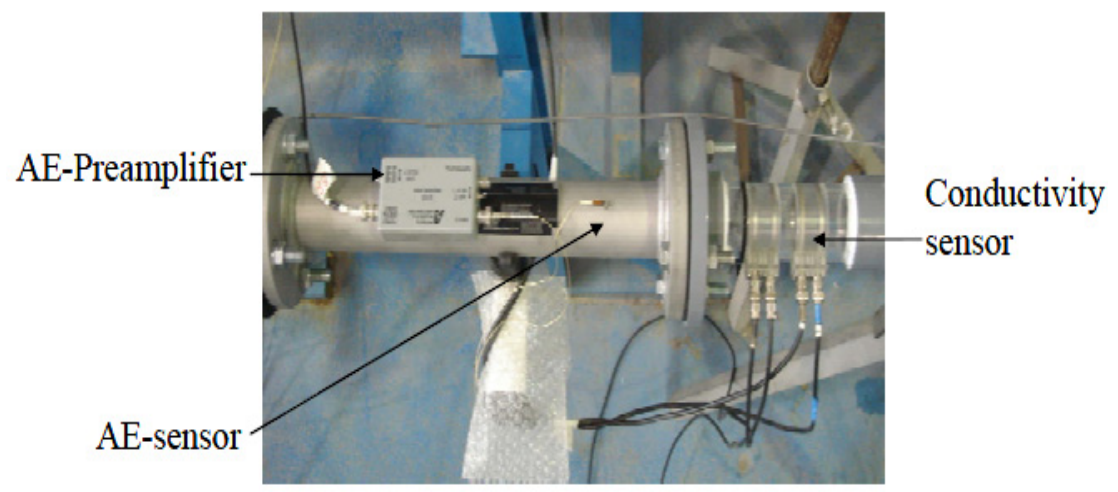

Figure 7: Test section: AE sensor, preamplifier and conductivity sensor.

Prior to the test; calibration work on the conductivity rings had been performed. The gas-liquid phase fractions were achieved by injecting known liquid volumes using an air compressor.

\section{Experimental results and discussion}

The results show that $\mathrm{AE}$ absolute energy steadily increased with the increase of VSG at all VSL velocities, see figure 8. The AE obtained could be associated with the flow pattern which was introduced by VSG. The results show evidence that the main contribution for increasing AE energy was VSG. In other words, the AE excitement was contributed by bubbles' activities. 


\section{WATERFALL PLOT OF ABSOLUTE ENERGY AND SUPERFICIAL VELOCITY}

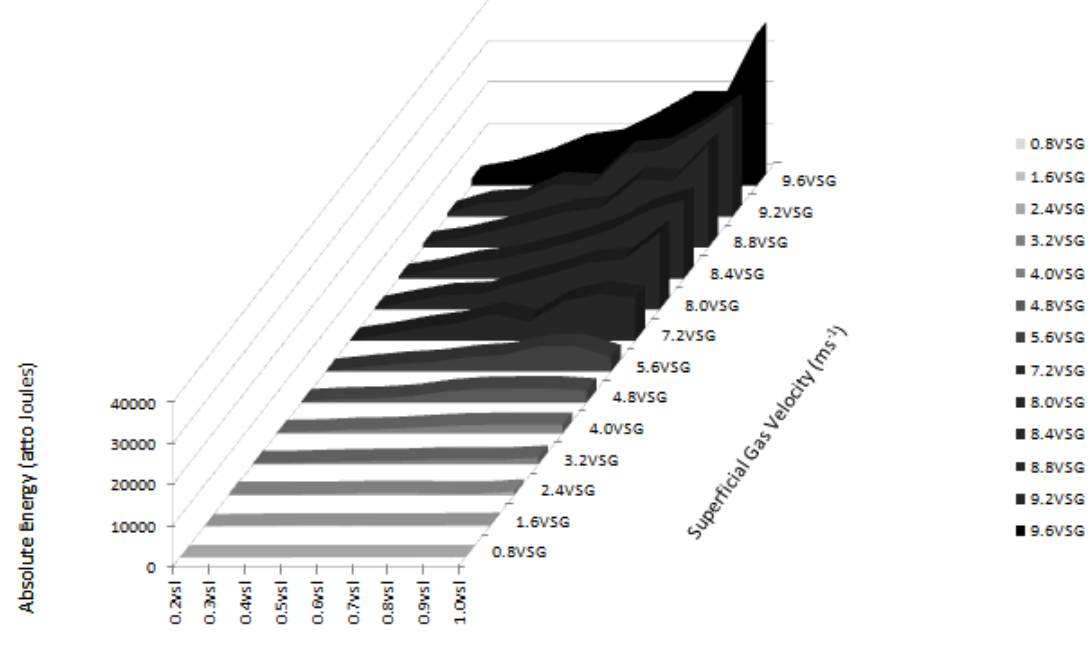

Superficial Liquid Velocity $\left(\mathrm{ms}^{-1}\right)$

Figure 8: $\quad$ AE absolute energy level measured at various VSL and VSG.

AE phenomenon of slug flow in a horizontal pipe could be correlated with the slug head and tail respectively, see figure 9. A time-frequency plot (figure 9) of an $\mathrm{AE}$ waveform associated with the slug showed frequencies of up to $500 \mathrm{kHz}$ at the earliest part of the AE slug wave. This high frequency was contributed by bubble activities as shown in figures 3 and 4 for single bubble inception and burst respectively.

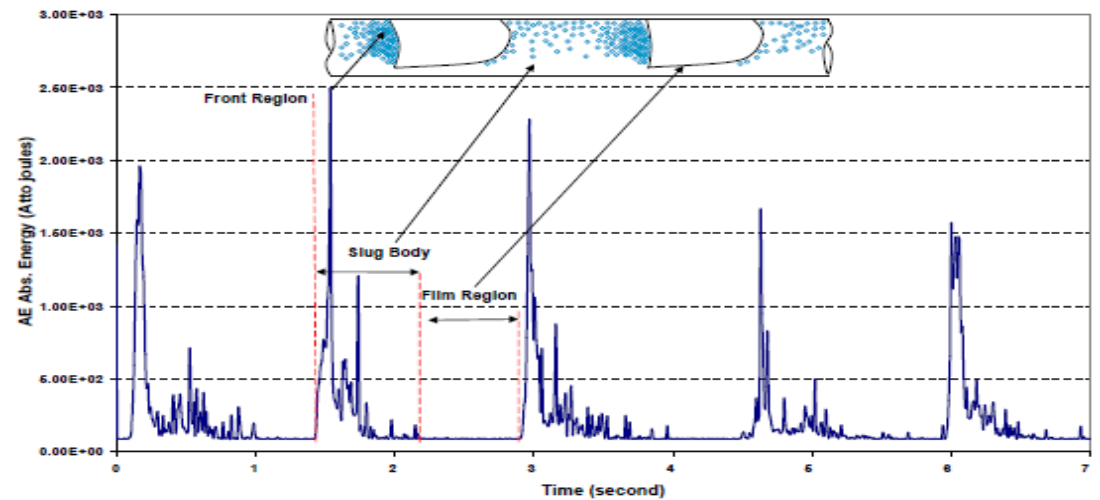

Figure 9: Typical AE Signal from fully developed slug flow. 
The results of WT of AE signal obtained from one of slug flow condition in horizontal pipe, which present both contour map and 3D-plot are shown in figures 10 and 11. Since the AE events are of short duration (tens of $\mu \mathrm{s}$ ) and of relatively high frequency, the $3 \mathrm{D}$ plots of the WT show very sharp peaks at high frequencies at about $40-50 \mu \mathrm{s}$. The contour maps (fig 10), shows the AE events appear in the form of a very closed space "island" shaped contours at average frequency around $400 \mathrm{kHz}$. Each AE signal appears as a distinctive peak "mountain" in the 3D representation. This implies that the high-energy AE signals, which have high amplitude and long duration, are composed of several closely spaced individual events. The wavelet as presented in figures 10 and 11 just showing an example of the characteristics of AE on slug flow.

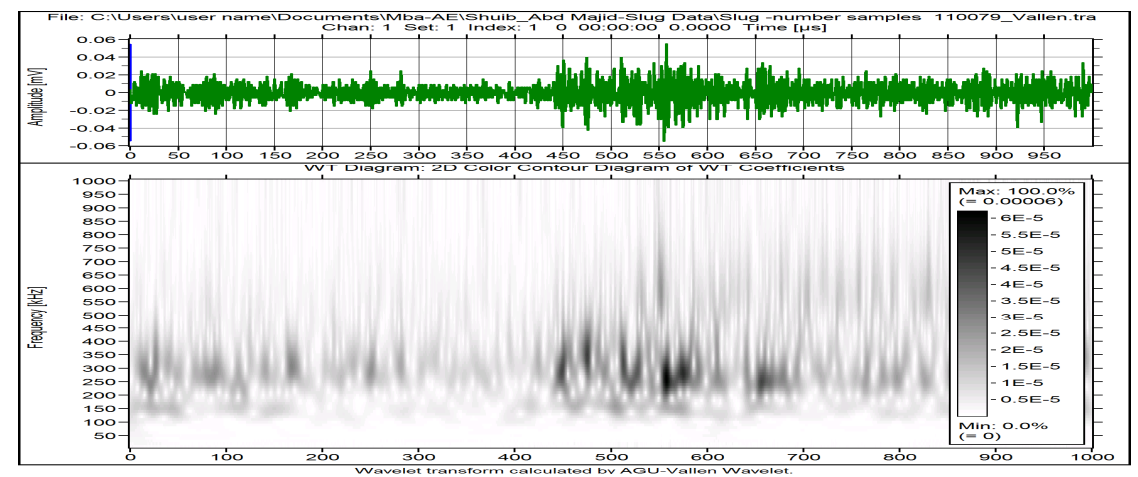

Figure 10: Example; time-frequency contour map of slug flow in horizontal pipe.

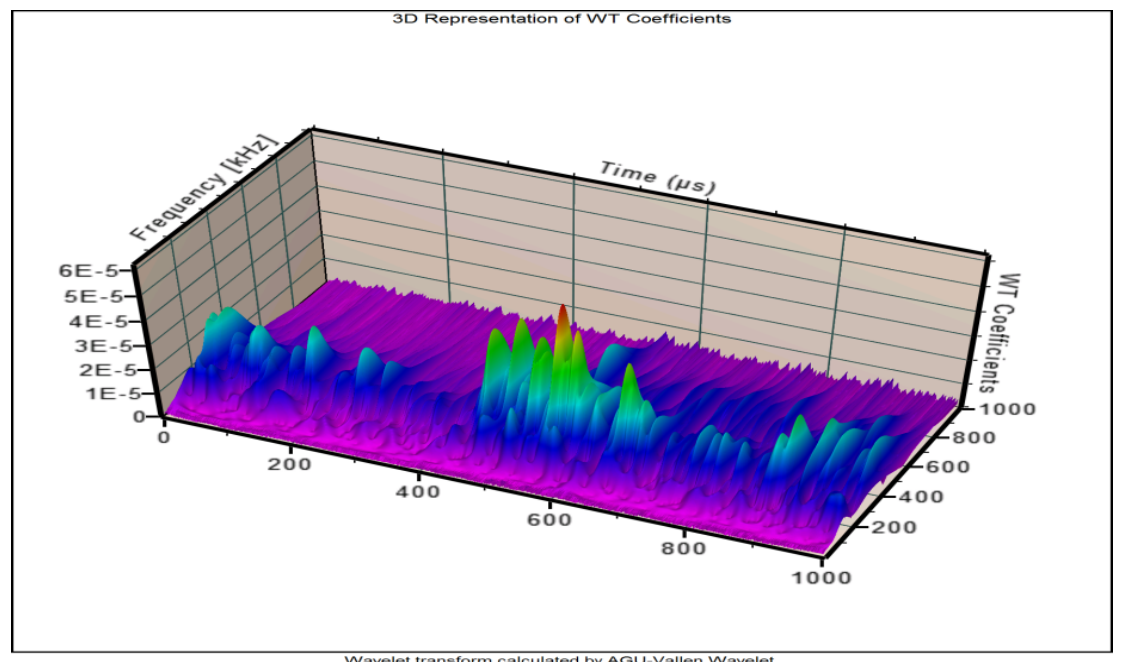

Figure 11: 3-D plot of wavelet transform (WT) of AE signal in fig 10. 
Figure 12 presents the measured GVF, calculated GVF and absolute energy level of $\mathrm{AE}$ signal acquired at varying $\mathrm{V}_{\mathrm{SG}}$ and a fixed $\mathrm{V}_{\mathrm{SL}}$ of $2.0 \mathrm{~ms}-1$. Results showed that any increase in GVF resulted in an increase in AE absolute energy. This manifests a correlation between AE (AE Technology) and the calculated and measured GVF (Conductivity rings).

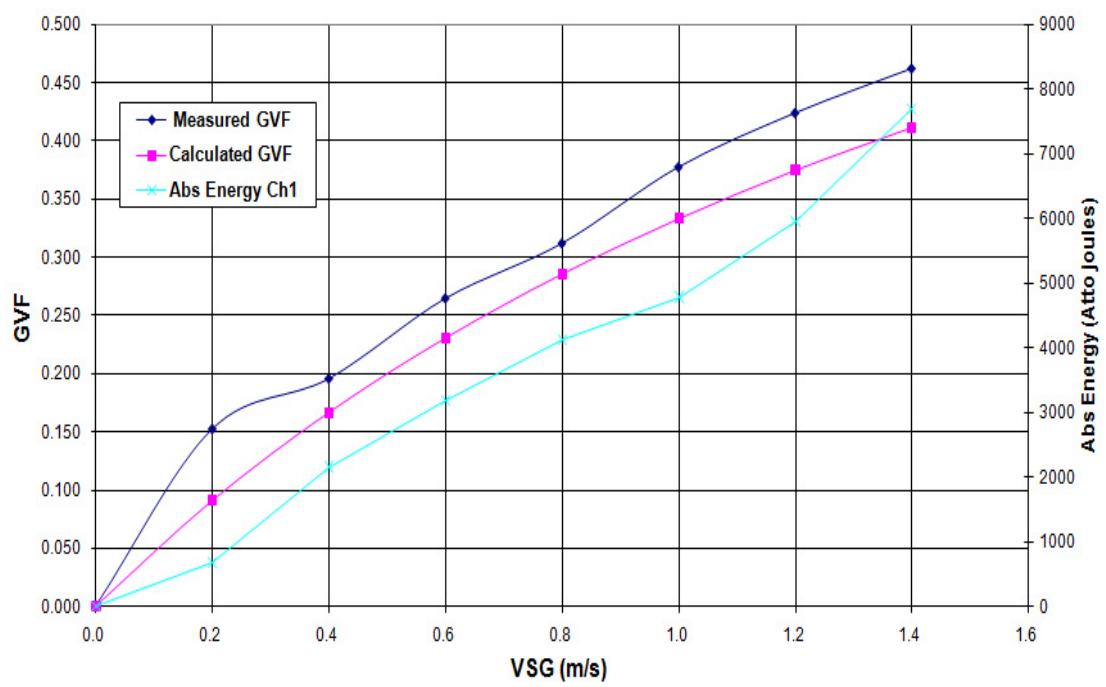

Figure 12: Correlation; GVF and AE abs energy levels at VSL $=2.0 \mathrm{~m} / \mathrm{s}$ for Ch1.

\section{Conclusions}

The sensitivity of an AE sensor has been demonstrated in this experiment to capture the emission from single bubble activities; inception and burst/collapse. The result showed the AE level associated with bubble activity increases as a function of bubble size and liquid viscosity. These findings confirmed the source of $\mathrm{AE}$ activities in two phase flow which comes from bubble dynamics; therefore it is evident that it provides a basis for assessing the applicability of AE to monitoring gas content in multi-phase flow. AE technology has the potential to be developed as a tool for flow pattern identification and monitoring in two phase flow in pipes.

\section{References}

[1] Yoon, D.J., Weiss, W.J. and Shah, S.P., Assessing damage in corroded reinforced concrete using acoustic emission. Journal of Engineering Mechanics, 273, March 2000. 
[2] Serrano, E.P and Fabio, M.A., Application of the wavelet transform to Acoustic Emission Signals Processing. IEEE Transaction on Signal Processing. Vol. 44, No. 5, May 1996.

[3] Yen, G., and Lu, H., Acoustic Emission Data Assisted Process Monitoring, ISA Transactions 41, 273-282, 2002.

[4] Al-lababidi, S., Addali, A., Yeung, H., Mba, D. and Khan, K., Gas void fraction measurement in two-phase gas/liquid slug flow using acoustic emission technology. J. Vib. and Acoustics, ASME, vol. 131, 6, 064501, 2009.

[5] Strasberg, M., 1956, Gas Bubbles as Source of Sound in Liquids. The Journal of the Acoustical Society of America, 28, 1, 1956.

[6] Leighton, T.G, The Acoustic Bubble. Academic Press, London, 1994.

[7] Mba, D. and Rao, R. B.K.N., Development of Acoustic Emission Technology for Condition Monitoring and Diagnosis of Rotating Machines; Bearings, Pumps, Gearboxes, Engines and Rotating Structures. The Shock and Vibration Digest, Vol. 38(1), pp. 3-16, 2006.

[8] Derakhshan, O., Houghton, J.R., Jones, R.K. and March, P.A., Cavitation Monitoring of Hydroturbines with RMS Acoustic Emission Measurements. World Meeting on Acoustic Emission, March 1989, p305-315, 1989.

[9] Brennen, C.E., Cavitation and Bubble Dynamics. Oxford University Press, New York, 1995.

[10] Neill, G.D., Reuben, R.L. and Sandford, P.M., Detection of Incipient cavitation in Pumps Using Acoustic Emission. Journal of Process Mechanical Engineering, ImechE, 211(4), pp. 267-277, 1997.

[11] Kuwahara, T., and Yamaguchi, H., Void fraction measurement of gasliquid two-phase flow using magnetic fluid. Journal of Thermophysics and Heat Transfer, Vol. 21, No. 1, pp. 173, 2007.

[12] Kloeppel, James E., Scientists measure energy dissipation in a single cavitating bubble. Physical Sciences Editor, (217) pp. 244-1073, 2002. Online. http://www.news.uiuc.edu/ii/02/0801/0724bubbleenergy_P.html $10 / 11 / 2002$

[13] Ross, D. Mechanic of underwater noise (Chapter 7). Topic in Cavitation, pp. 202-242. Pergamon Press, 1976.

[14] De-Bosset, A., Obreschkow, D., Kobel, P., Dorsaz, M. and Farhat, N., 2007. Direct effects of gravity on cavitation bubble collapse. 58 International Astronautical Congress 2007, pp. 1-5, 2007.

[15] Longuet-Higgins, M.S., Bryan R. Kerman and Knud Lunde, The Release of Air Bubble from an Underwater Nozzle. J. Fluid Mech, Vol. 230, pp. 365390, 1991.

[16] Leighton, T.G., Fagan, F.K. and Field, J.E., Acoustic and Photographic Studies of Injected Bubbles. Eur. J. Phys. 12, pp. 77-85, 1991.

[17] Manasseh, R., Bui, A., Sandercock, J. and Ooi, A., Sound emission processes on bubble detachment. Proc. $14^{\text {th }}$ Australian Fluid Mechanics Conf, Adelaide, South Australia, 9-14 ${ }^{\text {th }}$ Dec 2001, Vol. 1, pp. 857-860, 2001. 
[18] Deane, G.B., and H. Czerski, H., A mechanism stimulating sound production from air bubbles released from a nozzle. J. Acoust. Soc. Am (JASA Express Letters), pp. 126-132, 2008.

[19] Manasseh, R., Riboux, G. and Risso, F., Sound generation on bubble coalescence following detachment. Int. J. Multiphase Flow, pp. 938-949, 2008.

[20] Manasseh, R., Riboux, G., Bui, A. and Risso, F., Sound emission on bubble coalescence: imaging, acoustic and numerical experiments. 16th Australasian Fluid Mechanics Conference, Gold Coast, Australia 2nd-7th December 2007.

[21] Lauterborn, W. and Ohl, C.D., Cavitation Bubble Dynamic. Ultrasonics Sonochemistry, 4, pp. 65-75, 1997.

[22] Blake, J.R and Gibson, D.C., Growth and collapse of a vapour cavity near a free surface. J. Fluid Mech, vol. 111, pp. 123-140, 1981.

[23] Buogo S. and Canneli, G.B., Implosion of an underwater spark-generated bubble and acoustic energy evaluation using the Rayleigh model. Acoustical Society of America, 111(6), pp. 2594-2600, 2002.

[24] Obreschkow, D., Kobel, P., Dordaz, N., De Bosset, A., Nicollier, C. and Farhat, M., Cavitation dynamics inside liquid drops in microgravity. Physical review Letters, 97, pp. 1-4, 2006.

[25] Neppiras, E.A., Acoustic Cavitation. Physics Report (Review Section of Physical Letters) 61, No. 3, pp. 159-251, 1980.

[26] Mandhane, J.M., Gregory, G.A., and Aziz, K., A flow pattern map for gasliquid flow in horizontal pipes. International Journal of Multiphase Flow 1(1974), p 537-553, 1974.

[27] Shangguan, H., Casperson, L.W and Prahl, S.A. Pressure impulse during microsecond laser ablation. Applied Optics, Vol.36, No. 34, pp. 9034-9041, 1997.

[28] Benjamin, T.B., and Ellis, A.T., The collapse of cavitation bubbles and the pressure thereby produced against solid boundaries. Phil. Trans. R. Soc. Lon. 260, no. 1110, pp. 221-240, 1966.

[29] Isseline, J.C., Alloncle, A.P. and Autric, M., On laser induced single bubble near a solid boundary: Contribution to the understanding of erosion phenomena. Journal of Applied Physics, vol. 84, no 10, 1988.

[30] Clayton T. Crowe, Multiphase Flow Handbook, Taylor and Francis, ISBN10: 0849312809, 2005. 